\title{
¿QUÉ ES LA CARICATURA?
}




\section{Resumen}

El siguiente artículo de investigación extrae las principales características de la caricatura recogidas a partir de las experiencias artístico-pedagógicas y el estudio que se llevó a cabo en el proyecto de investigación Caricatura: Educación y procesos artísticos de los estudiantes del grupo Milán-CLAN Castilla, realizado en la Licenciatura de Artes Visuales de la Universidad Pedagógica Nacional de Colombia. Esta permitió reconocer la caricatura como una herramienta importante para el desarrollo de contenidos dentro de la educación artística, además de promover la creación de una estética propia, el conocimiento de lo cómico, el fortalecimiento de los conceptos fundamentales de las artes visuales, el desarrollo del pensamiento crítico, nuevas dinámicas en la educación y las relaciones horizontales así como nuevas formas de ver el mundo. A partir de las caricaturas de los personajes iconográficos se generó la construcción de pensamientos, valores y convicciones. Este artículo presenta los principales análisis desarrolladas en torno a la caricatura (estética de lo cómico, fisionomía y morfología) dentro de la enseñanza y las posibilidades de su práctica para la comprensión de lo visual.

Palabras clave: caricatura; educación artística visual; estética de lo cómico; morfología; fisionomía; procesos artísticos

\section{What Is Caricature?}

\section{Abstract}

The following research paper presents the main characteristics of caricatures gathered from the artistic-pedagogical experiences and the study carried out in the research project Caricatura: Educación y procesos artisticos de los estudiantes del grupo Milán-CLAN Castilla, conducted in te BA in Visual Arts of Universidad Pedagógica Nacional de Colombia.

This allowed us to recognize caricatures as an important tool to develop contents in arts education, aside from promoting the creation of one's own aesthetic, the knowledge of the comic, the strengthening of the fundamental concepts of visual arts, the development of critical thinking, new dynamics in education and horizontal relationships, as well as new ways of seeing the world. Based on the caricatures of iconographic characters, the construction of thoughts, values and convictions was generated. This paper presents the main analyzes made about the caricature (aesthetics of the comic, physiognomy, and morphology) within teaching and the possibilities of practice for the understanding of the visual part.

Keywords: caricature; visual artistic education; aesthetics of the comic; morphology; physiognomy; artistic processes

\section{O que é a caricatura?}

Resumo

O seguinte artigo de pesquisa abrange as principais características da caricatura coletadas a partir das experiências artístico-pedagógicas e o estudo realizado no projeto des pesquisa Caricatura: Educación y procesos artísticos de los estudiantes del grupo Milán-CLAN Castilla, realizado na Licenciatura de Artes Visuais da Universidade Pedagógica Nacional da Colômbia. Esta permitiu reconhecer a caricatura como uma ferramenta importante para o desenvolvimento de conteúdos dentro da educação artística, além de promover a criação de uma estética própria, o conhecimento do cômico, o fortalecimento dos conceitos fundamentais das artes visuais, o desenvolvimento do pensamento crítico, novas dinâmicas na educação e as relações horizontais, assim como novas formas de ver o mundo. A partir das caricaturas dos personagens iconográficos geramos a construção de pensamentos, valores e convicções. Este artigo apresenta as principais análises desenvolvidas sobre a caricatura (estética do cômico, fisionomia e morfologia) dentro do ensino e as possibilidades de sua prática para a compreensão do visual.

Palavras-chave: caricatura; educação artística visual; estética do cômico; morfologia; fisionomia; processos artísticos
La caricatura ilustra la realidad como seres humanos, con sus virtudes y defectos, con toda su complejidad, permite mostrar el lado jocoso de la vida, es el manifiesto de la risa al observar la realidad. Esta exagera la realidad individual frente a la percepción de las cosas o circunstancias del momento o las personas alrededor. Como herramienta permite expresar sin pena lo que se piensa y en algunos casos es la que, a partir de un error, produce una obra visual que, como en una metamorfosis, puede convertirse en algo bello para el espectador o transformar los defectos del ser humano en virtudes.

El arte de la caricatura no se puede catalogar como algo bello o feo, pues igual que las artes visuales, depende de la percepción de cada sujeto, su creación está enmarcada dentro de la libertad de las emociones sin ningún condicionamiento; asimismo, suscita el pensamiento visua creativo y crítico a partir de la percepción visual de la imagen en la que se genera una destreza para la inteligencia mediante la experiencia (Rodríguez, 2003).

Lo anterior es posible a partir de la educación de la mirada y el desarrollo del trazo, en los que cada persona desarrolla una estética propia de su realidad exagerada al tiempo que puede, a partir del arte, tener una relación y generar un impacto emocional con su entorno social.

En Colombia la caricatura se considera como una acción artística ${ }^{1}$ y un fenómeno cultural que produce un artista visual que está mediado por su relación con las personas; son ellas el objeto de inspiración y las protagonistas de esta forma de expresión.

De esta manera, la caricatura es vista como una labor en la que un dibujante plasma mediante el trazo sobre el papel su perspectiva de la persona, los aspectos que configuran su identidad y su contexto. A su vez, es un arte condicionado por lo inmediato y lo impredecible, es decir, el dibujante crea en el momento, sobre el tiempo, sin ser consciente del resultado. De igua modo, es un producto que, una vez en manos de su receptor, escapa del artista que lo crea

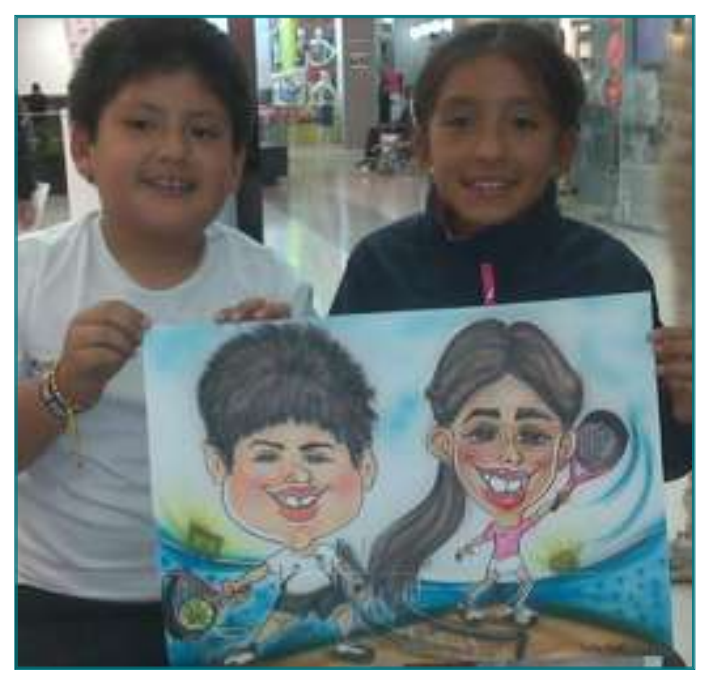

Figura 1. Sin título. Caricatura de dos niños en donde se evidencia que la obra no termina en manos del artista sino en las de la persona que se dibuja. Esta es una herramienta de comunicación educativa ya que además de los aportes técnicos también representa una caracterización crítica y analitica de las personas. Fuente: elaboración propia. 
Por otro lado, hay artistas visuales que utilizan la caricatura como medio de expresión de sus ideas en form satírica o sarcástica, exponiendo temas sociales álgidos para el país en los medios de comunicación impresos como revistas o periódicos.

\section{Problemática}

Actualmente, la caricatura no es reconocida en los lineamientos artísticos de la ciudad de Bogotá dentro del currículo de la Secretaría de Educación, en la cual se reconoce a la pintura y el graffiti, sin embargo, infortunadamente, esta no se reconoce en ninguna de sus líneas dentro de las artes visuales.

Titulada Currículo para la excelencia académica y la formación integral, Orientaciones para el área de Educación Artística (2014), la propuesta del Centro de Interés de Artes Plásticas y Visuales de la Secretaría de Educación de Bogotá hace un énfasis en dos puntos:

- Historia del arte (vanguardias artísticas).

- Desarrollo del pensamiento creativo: pintura, escultura modelado, graffiti, dibujo artístico y técnico, posters y vitrales.

A pesar de ser parte de las artes visuales, la caricatura no se evidencia ni se reconoce dentro del currículo educativo de estas, limitando las múltiples posibilidades del desarrollo y el pensamiento artístico. Además, no es asumida como una posibilidad dentro del taller, como propuesta dentro de los docentes, es decir, no está visibilizada dentro de las líneas para abordar la educación, razón por la cual se transgrede a los procesos históricos que han sido llevados por Carraci, George Cruikshank y Francisco de Goya, precursores de la caricatura en el mundo y en la ciudad. A pesar de tener grandes representantes y de ser asumida desde otras áreas de conocimiento como la comunicación no se incluye dentro de los procesos de enseñanza, por lo que es de vital importancia que haga parte de cualquier currículum que pueda generar nuevas apuestas artísticas.

Según los lineamentos de la Secretaría de Educación de Bogotá, en el documento citado anteriormente, se plantea lo siguiente:

Se desarrollarán procesos formativos que provean insumos técnico-expresivos, en prácticas colectivas yce chas colchivas y cre mensionalidad y la tridmensionaldad, $\mathrm{y} a$ aplicación de nuevas tecnologías digitales de acuerdo con el proceso de apropiación técnica, conceptual, desarrollo creativo y crítico de cada estudiante, según el ciclo. Como parte fundamental del proceso de formación, todo lo anterior se llevará a escena a través de instalaciones, exposiciones, performances y otras maneras de socialización propias de este tipo de expresión artística. (2014, p. 53).

De acuerdo a lo anterior, la Secretaría de Educación busca procesos que provean insumos técnico-expresivos en el aula para generar prácticas colectivas y creativas; si la caricatura fuera visible dentro de estas, tendríamos una herramienta que nos ayudaría a fortalecer y ampliar conceptos como por ejemplo la comprensión de una forma o un volumen en particular, dándole total intencionalidad a su esencia en el proceso de creación por medio de la caricatura fisonómica. Igualmente, se lograría un desarrollo de la estética de lo cómico que permite no solo analizar en profundidad la morfología y forma de las cosas sino también un pensamiento más critico en los estudiantes sobre sí mismos, sus allegados y su contexto social en general.

Además, mediante el análisis de los contextos de los personajes y sus composiciones, los estudiantes pueden desarrollar nuevos criterios artísticos, una actitud más crítica frente a las personas, su carácter y sus contextos, una comprensión de la representación exagerada, un pensamiento visual más amplio, el desarrollo del trazo suelto y de su propio estilo, mayor habilidad en la exploración de materiales que refleja una mejor interpretación de las artes visuales y de otras líneas como el retrato, la pintura y la escultura; todas estas son temáticas que se trabajan transversalmente con la caricatura, siendo esta un instrumento para la expresión de ideas, sentimientos y vivencias que generan un pensamiento visual más profundo y un acercamiento más armónico con la cultura que nos rodea.

Actualmente, vemos como en la cultura visual se utiliza la caricatura como herramienta expresiva, como, por ejemplo, los dibujos animados, en los cuales existe una representación de personajes icónicos a partir de su fisionomía, generando múltiples significados, símbolos y representaciones para las personas.

Entre estas se encuentran Los Simpson, en formato de animación, creada por Matt Groening, en los cuales toma forma créticono her vida cotidina de una famili estadounider e. El chavo del 8 , una serie de televisión cómica mexicana, creada y protagonizada por Roberto Gómez Bolaños, tuvo una crítica negativa cuando salió al aire, según la crítica por vulgar, boba e insulsa. Sin embargo, el programa sigue al aire en diferentes canales del mundo ya que posee una problemática universal. Otra serie animada basada en la caricatura es South Park, creada por Trey Parker y Matt Stone. Dirigida al público adulto, utiliza la sátir y el humor negro como crítica a la sociedad actual. Asimismo, La Abeja Maya, una serie japonesa producida por Nippon Animation Company en 1975, utiliza la caricatura como herramienta para el desarrollo de competencias en los niños basándose en el libro del escritor alemán Waldemar Bonsels de1912. Los anteriores programas de televisión hacen parte de nuestro cotidiano y de nuestra cultura visual y su base está

desarrollada a partir de la caricatura en interacción con otras disciplinas.

Cuando hablamos de "cultura visual", hablamos de todas aquellas realidades que cada vez van teniendo un papel relevante en nuestra forma de ver el mundo, como por ejemplo el desarrollo de la perspectiva en el renacimiento o la invención del cine en el siglo xIx, el cual no aportó el concepto de los planos más allá de la historia.

Actualmente, la cultura visual está constituida por imágenes producidas y manipuladas por el hombre dándoles significados e intenciones, de modo que todas las caricaturas animadas y actuadas como es el caso del chavo del 8 constituyen nuestra cultura visual. En palabras de Latorre:

Vivimos en un mundo visual, desde que nos despertamos en las mañanas nuestros ojos están percibiendo múltiples imágenes, objetos, lugares, espacios, que nos dicen

algo: un mensaje, un significado, etc. Así los medios de comunicación y las tecnologías se han desarrollado de tal manera que la cultura visual ha tenido una mayor fuerza. Por tal motivo la educación artística visual nos invita a entender esta realidad que nos afecta de manera constante. (2015, p. 2).

El motivo de la existencia de la educación artística responde a la comprensión de nuestros contextos visuales pues esta busca desarrollar el pensamiento visual, entender de forma crítica lo que nos rodea, comprender todas nuestras creaciones y desarrollar en el ser humano ese lado sensible que es capaz de percibir la realidad 
no desde una forma neutra o simplemente consumista, sino desde el análisis y una postura reflexiva frente a los contenidos. Es por eso que la educación artística tiene que reconocer la participación e importancia de diversos aprendizajes y aportes de la caricatura, la cual se relacionan constantemente con los contextos culturales contemporáneos, permitiendo así su propio desarrollo.

\section{Lo cómico en la caricatura}

Entender la caricatura desde lo cómico genera una actitud crítica frente al ser humano que se ridiculiza, encierra un sentimiento de optimismo histórico que afirma la vida y juzga sus fenómenos (Rodríguez, 1992).

Lo cómico es una categoría de la estética que expresa la disconformidad, tiene un valor social y un papel ideológico fundamental. También tiene un carácter objetivo pues se manifiesta en los fenómenos de la vida, aborda lo pasado y lo contemporáneo en la sociedad, lo burdo y lo mediocre (Rodríguez, 1992).

La estética de lo cómico genera contradicciones entre el ideal y la realidad, creando discordancias inesperadas como la exageración, la disminución física, la sorpresa, el ritmo, el malentendido, medios inconvenientes, etc., logrando así lo que más la caracteriza: el humor y la sátira (Rodríguez, 1992).

El humor está supeditado a un contexto histórico ya que cumple una función social, es decir, la inspiración de la caricatura es un personaje icónico; para representarlo debemos analizarlo y reinventarlo, un proceso que da cuenta también de el medio del autor, lo que genera entonces una mezcla de contextos particulares.

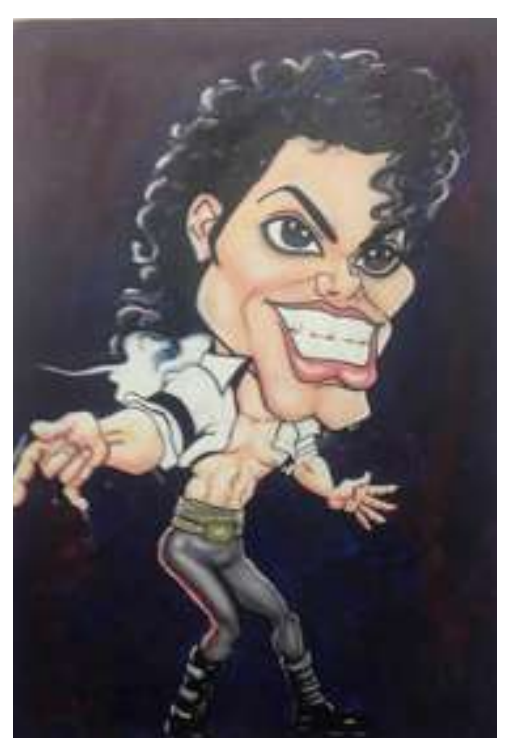

Figura 2. Sin titulo. En este ejemplo de caricatura fisionómica del ícono del pop Michael Jackson vemos el estudio, el análisis y la exageración de las facciones del personaje creado, pero también por el hecho de ser un personaje icónico nos remonta a una historia, es decir, las caricaturas llevan siempre a pensar un contexto en sí. Fuente: Fundación Jóvenes con Talento.

Otras características importantes dentro de lo cómico son la broma y la ironía esta última es el planteamiento de una idea en forma hiriente destacando de forma burlesca un conflicto o crítica (Bergson, 1927). Por otro lado, destacando lo positivo de la estética de lo cómico, la sátira es una denuncia airada y crítica los hechos de gran movilidad histórica (Barrio, 2010), la cual puede encontrarse solamente desde la representación misma de la caricatura.
Dentro de las teorías existentes en la estética del arte, lo cómico está dentro de la categoría de lo monstruoso, que le añade a la caricatura un grado de grotesco dentro de las valoraciones socio-históricas. Este concepto es visto desde discursos doctrinales como algo maléfico o que conlleva al pecado, que genera temor, asco o fascinación, por lo que finalmente lo monstruoso se convierte en un imaginario de lo informe (Barrios, 2010).

La estética de lo cómico, que también es llamada de lo informe, ${ }^{2}$ sobrepasa los límites del canon de la belleza, lo que permite la risa y el dolor desde una perspectiva problemática: es el pensamiento de la identidad lo que brinda alegría en la vida de la comunidad, desbordando las emociones humanas, lo risible y lo feo (Bergson, 1927).

En su libro La risa, $\mathrm{H}$. Bergson 3 propone varias ideas de lo cómico, lo que nos llevan a las principales características de la caricatura; en palabras del autor: "Toda deformidad que se pueda imitar por parte de una persona bien conformada puede ser cómica" (1927, p. 86). En este sentido, desde la deformidad se puede componer una obra sin que su esencia sea deforme en sí, es decir, mediante el análisis visual de un personaje, junto con sus formas perfectas, se puede exagerar sus principales características físicas, creando así una representación ideal de un retrato exagerado.

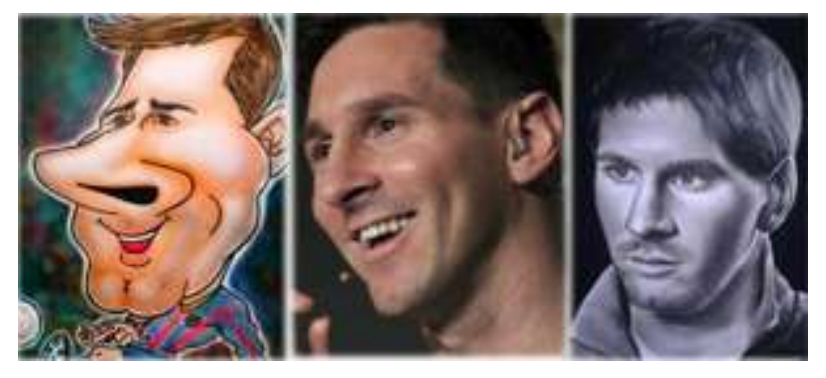

Figura 3. Sin titulo. En esta imagen se aprecia un personaje icono de la cultura contemporánea en el fútbol: Leonel Messi; a su derecha se puede ver una representación de retrato de Luis Bayona y a su izquierda la representación de una caricatura de Martin $B$. Pineda que no busca la deformidad por sí misma alejada de las características propias del rostro sino exaltando su esencia. Fuente: Luis Bayona y Martín B. Pineda.

Según Bergson, "se ridiculiza naturalmente sin ser deforme por nacimiento, sino en su esencia hecha risa o jocosidad" (1927, p. 96). A partir de esta idea surge la

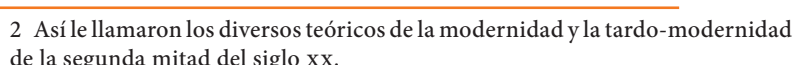

3) Filosofof francés ganandor del Premio No
estudios sicologicos y propuestat téricas. problemática de la fealdad cómica. A pesar de que los primeros teóricos enunciados se refieren a lo cómico como fealdad, desde la caricatura lo cómico no necesariamente es feo sino que más bien se refiere a la perfección de la exageración.

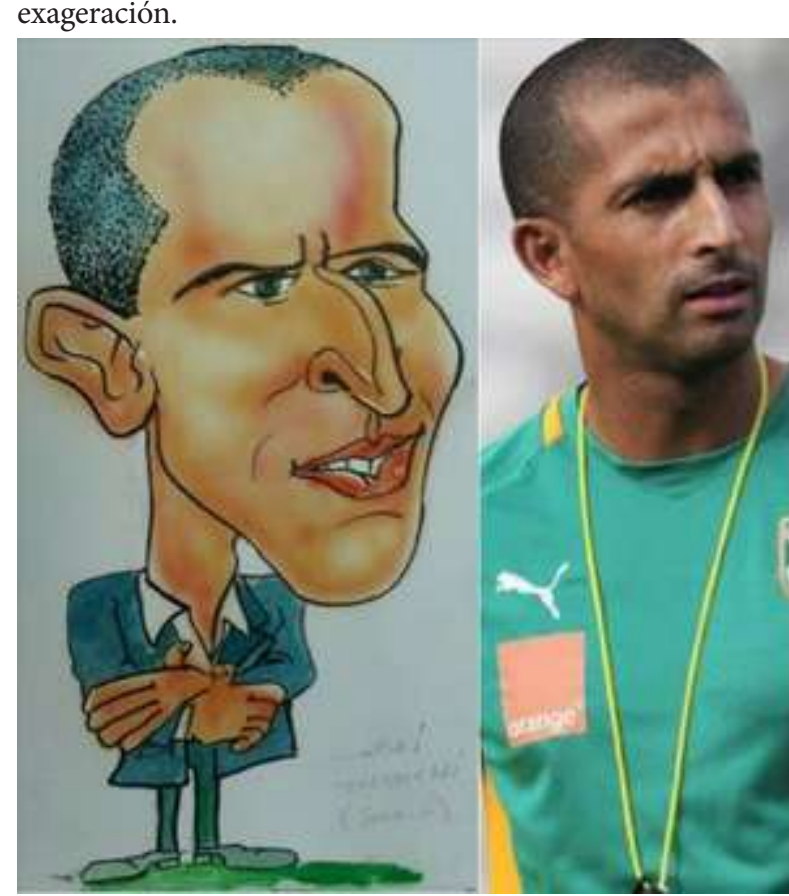

Figura 4. Sin título. Esta caricatura de Abril Lamouchi muestra la exageración perfecta en cuanto exagera solo lo más predominante del personaje, llegando así a lo que se llamaría un ideal de la deformidad con sentido.

Independientemente del estilo de cada artista, lo que se quiere resaltar aquí es la deformidad con un análisis, un estudio y una construcción visual del personaje en cuestión. Fuente: Martín Bayona.

Para Bergson "un efecto de un gesto es más cómico cuando su causa es más natural, es decir, entre más natural sea un gesto más cómico es" (1927, p. 33). Analizando esta afirmación, la intención de la caricatura no es hacer una representación falsa de un sentimiento, acción, facción o figura, sino plasmar lo más fielmente posible los gestos $\mathrm{y}$ emociones del personaje que se va a representar. Por ejemplo, en la caricatura de A. Lamouchi, le vemos fruncir el ceño de las cejas e igualmente podemos apreciar las facciones más predominantes como su cuello ancho y fuerte, su frente amplia, su larga nariz junto con su curvatura perfecta, etc. Como las personas dicen coloquialmente: un simple gesto captura nuestra alma; cuando logramos representar ese gesto o lo más característico del personaje es cuando vemos una estética de lo cómico. 
Con la estética de lo cómico, los estudiantes o las personas en general logran ver contenidos con gran risa e ironía sobre algo que tal vez en realidad sea una situación triste, pero que, finalmente, gracias a la caricatura, es pensado desde una postura crítica sobre las personas, los contextos y las historias particulares.

Bergson (1927) comenta que dentro de sus representaciones la risa significa las contorsiones de la naturaleza en donde cada artista percibe y se expresa. Se podría decir entonces que la estética de lo cómico en la caricatura es una expresión jocosa que no solo muestra un gesto cómico en el rostro sino que busca manifestar las cualidades más predominantes del sujeto o su contexto, lo que evidencia percepciones de lo chistoso, de la risa de cada ser humano; como diría el autor "es visibilizar un gesto u emoción en su máxima expresión de lo visible” (Bergson, 1927, p. 92).

La caricatura genera entonces nuevos paradigmas naturales de la perfección, es decir, también hace parte de la estética de la belleza, pues su deformidad es medida a las proporciones exactas del personaje; se da protagonismo a su personalidad, su carácter, sus rasgos y acciones y cuando las personas, o en nuestro caso los estudiantes, se acostumbran a su apreciación, esta se convierte en un paradigma natural. "La estética de lo cómico tiene gracia", afirma Bergson (1927), lo cual significa que se puede expresar las múltiples posibilidades de la esencia de las personas y explorar sus representaciones, sus gestos y sus intenciones en cada composición.

Según el mismo autor, la belleza de la caricatura se

encuentra en su armonía con la gracia, es decir, se encuentra en las representaciones artísticas a través de la fidelidad de la caracterización del personaje.

Un ejemplo son las prácticas artísticas que realizaron los estudiantes del grupo Milán para abordar la relación entre lo cómico y la gracia. A la hora de la realizar el taller se generaron actitudes de burla hacia el personaje o la imagen en sí, y al avanzar el proceso de aprendizaje, los estudiantes se reían a modo de reflexión sobre el gesto o el contexto que había más a fondo, entendiendo los pequeños detalles, en un ejercicio más analítico y profundo.

Algunos estudiantes lograron llegar a lo cómico de la caricatura en sí, entendiendo la gracia y la armonía de las formas, lo que es un ejemplo de las primeras ideas de Bergson sobre la estética de lo cómico: una representación que da vida al personaje (Bergson, 1927).
La estética de lo cómico es una teoría que contiene muchos conceptos, sin embargo, esta es la que permite la representación más fiel del sujeto en la caricatur. Una de las características más importantes es la identidad, eso que expresa la cotidianidad, la moda, las costumbres, los ambientes, etc., y que genera al final la risa y la reflexión en el espectador. Así

No puede existir lo cómico fuera del

contexto humano; hombre, mujer. Este es el que le da el sentido vivo de lo cómico lo cual quiere decir que los objetos $o$

contextos nos producen risa gracias a la

existencia del que hace reír, el hombre.

(Bergson, 1927, p. 25).

De lo anterior se puede deducir que a pesar de haber diferentes manifestaciones artísticas en la caricatura, todas se remontan a la representación de un personaje que surgió a partir de los géneros básicos hombre o mujer, es decir, a pesar de que caricaturicemos un Transmilenio (transporte público de Bogotá Colombia), un celular o un objeto en general, siempre lo relacionamos con el género femenino o masculino; en la actualidad y dado a los nuevos géneros, las representaciones se pueden extender a personajes asexuado o de género indefinido, sin embargo, estos estarán enmarcados en esa dualidad inicial.

La estética de lo cómico es un mundo

de insensibilidad. [...] Cuando aislamos una acción de su sentimiento, se genera lo cómico, para que este fenómeno se

produzca en alguien debe éste alejar todo sentimiento de piedad o afecto contra lo que ríe, una risa o un acto cómico que se produce en la colectividad o complicidad de otros. (Barrios, 2010).

Una de las características más importantes de la caricatura es dar a conocer las dinámicas sociales que nos llevan a inducir conceptos, fenómenos y manifestaciones de toda índole, de esta manera, "un efecto cómico se hace notar cuando en su accionar está plasmado las

Es mediante las dinámicas sociales evidenciadas en la caricatura que se desarrolla la siguiente característica: "lo cómico es un contraste intelectual, es la sensibilidad de lo absurdo, es inconsciente, tiene una 
significación y función social" (Bergson, 1927). En ella se permite la creatividad de lo absurdo basado en personajes, hechos y contextos reales los cuales siempre generan pensamientos. Es la representación de algo, haciéndolo ver estúpido, generando así la critica a partir de la burla, por ejemplo, el distraído es causa de chistes por estar en su situación pasada y no en su realidad presente (Bergson, 1927).

Otra característica es el vicio, como Bergson lo llama, que en otras palabras es la identidad del personaje, ya que la caricatura también es burlada desde lo que hace o lo que representa. Se podría decir entonces que la caricatura es sinónimo de lo cómico y de la risa.

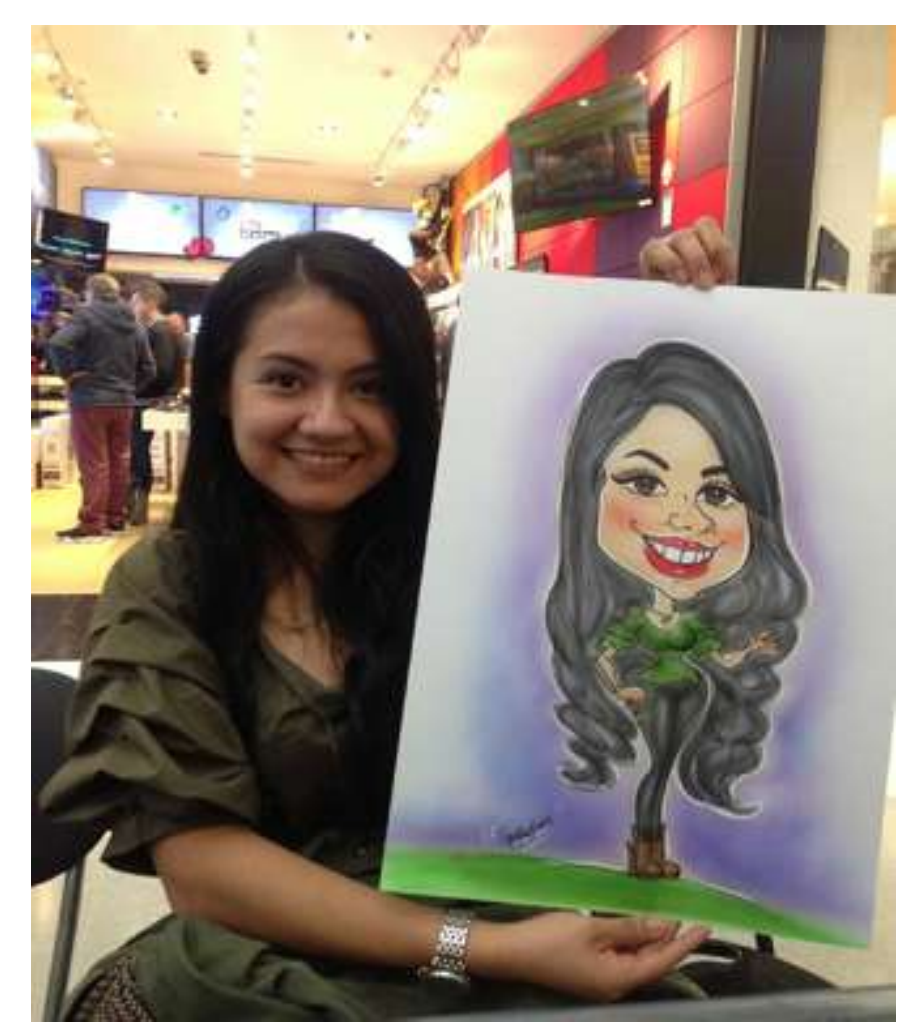

Figura 5. Sin título. En esta obra que utiliza la técnica en aerografia se demuestra la similitud de las facciones, las formas del cráneo y el contexto social por medio de la vestimenta y la estética visual. También se resalta la armonía de la composición. Fuente: elaboración propia.
José Luis Barrios ${ }^{4}$ reconoce al cuerpo como un lugar de formación y deformación de los límites, sin identidad, donde habla el cinismo y lo grotesco cómico. Estas características tienen una relación con el poder, el dolor y el terror, que transitan por los lugares carnales de la risa cínica y la pérdida de lo sagrado, donde lo risible es un defecto y una fealdad que no causa ni dolor ni ruina (Barrios, 2010).

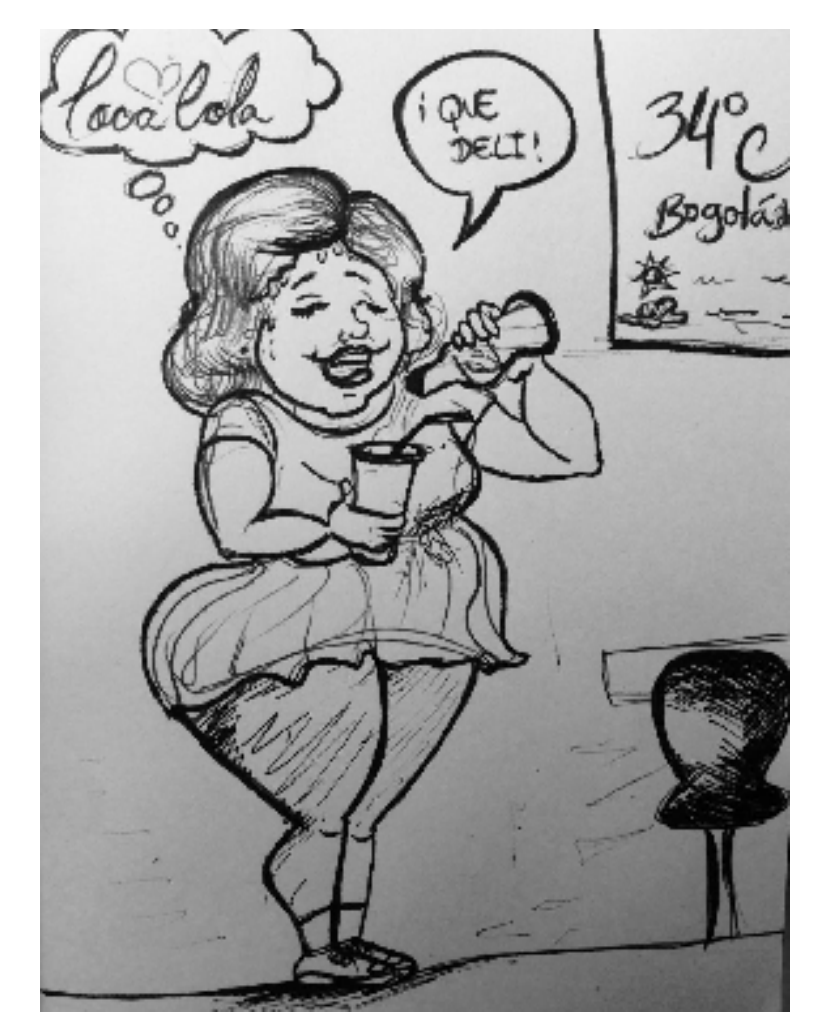

Figura 6. Sin titulo. En esta caricatura se pueden leen varios fenomenos como el amor por las gaseosas, la utilización del pitillo, los principios de obesidad mórbida, y, por ende, la utilización de zapatos bajos, el alto clima exagerado en la ciudad haciendo sátira al fenómeno de la niña, en fin, se inducen varias características como el diseño de la silla que dan cuenta de que es una caricatura de nuestra época (siglo XXI), es decir, una caricatura convencional. Fuente: elaboración propia.
Análisis de la caricatura en la educación

A partir de la investigación se desarrolla a la caricatura como categoría de análisis, la cual desarrolla el concepto y características formales del retrato cómico, enunciando sus principales representantes, para mostrar los diversos estilos, su proceso en el tiempo y sus contextos. El lector encontrará la relación de este arte con los contextos sociales y los pensamientos de los estudiantes, lo que permite evidenciar algunas de sus posturas hacia sus gustos visuales y la cultura social que determina sus producciones artísticas.

Asimismo, se enuncian los tipos de caricatura y las técnicas para su desarrollo y a su vez se explica la caricatura fisionómica, que fue la que se desarrolló con los alumnos. Es por medio del aprendizaje de esta que el grupo de investigación logró analizar personas, personajes, contextos culturales, estéticas visuales, modas, cuerpos, etc., generando así referentes que permitieron el desarrollo artístico y cultural de cada uno.

Las subcategorías que surgieron fueron:

6.5.2.1. Fisionomía

6.5.2.2. Morfología

6.5.2.3. Personajes Icónicos

6.5.2.4. Contextos Sociales y Medios

\section{Caricatura en la educación artística}

Al definir la caricatura fisonómica, al inicio del proceso de los talleres realizados, los estudiantes la relacionaron con dibujos animados, luego, a medida que se abordaba en sus diversas posibilidades, fueron descubriendo otros conceptos. En un primer momento, reconocieron las diversas facciones de un rostro de acuerdo a su raza y genética, tomemos como ejemplo el biotipo humano (Ectomorfos, Mesomorfos y Endoformo) (Barboza, 2013); se ponen como ejemplo las caderas voluptuosas de personas y en contraste se desarrollan más los pulmones generando mayor voluptuosidad en el tórax; ${ }^{5}$ es así como los estudiantes empezaron a educar la mirada y a desarrollar la observación mediante la apreciación de las formas, identificando la voluptuosidad o las formas atenuadas de la fisionomía o de la morfología.

Otra característica que se manifestó a partir de un ejercicio que se desarrolló en el aula fue la relación de objetos cotidianos o comida con las formas del cuerpo, para construir a partir de estos una parte del cuerpo, facilitando así su comprensión.

Los alumnos también aprendieron los diferentes tipos de cráneos y formas del rostro para entender la composición de una determinada facción, y además se estudiaron tipos de rostros a partir de figuras geométricas y personalidades.

A su vez, se hizo énfasis en que se debía exagerar las partes más preponderantes de la persona, las cuales no siempre son una parte del rostro sino más 
bien una emoción, y es así como se llegó a entender la combinación perfecta entre gestos y facciones. En esta se relacionan las expresiones con los estados de ánimo para crear la personalidad del personaje y de este modo otorgar al rostro características físicas más sobresalientes que conforman el gesto (Rouges, 1959). Los alumnos también aprendieron a representar la disminución del cuerpo en sus diferentes partes de acuerdo a la intención visual, es decir, si querían que su aspecto fuera cadavérico o por el contrario gordinflón.

De igual forma se estudió la fisionomía del cuerpo en sus diversas exageraciones las cuales pueden identificar al personaje; a partir de ejemplos de personas cercanas, cuadernos, fotografías de famosos $e$ ídolos, o fotografias familiares, se representaba, se compartían vivencias o conocimientos, realizando así un análisis del sujeto en su estilo visual, sus creencias, su carácter y la cultura que lo identifica.

Los gestos generan emociones, es así como a partir de diferentes talleres como máscaras en yeso, dibujo, altorrelieve y escultura se desarrollaron gestos como tristeza, felicidad, asombro, rabia, admiración, ironía, etc., y se encontraron la diversidad de facciones como las múltiples cejas existentes o la exageración de una expresión.

Además de reconocer la morfología de las personas, se analizó la fisionomía, las formas y los volúmenes de los cuerpos con el fin de generar efectos visuales de volumen o figuras holgadas o cóncavas. El reconocimiento del otro y de ellos mismos como un mundo lleno de volúmenes, formas, facciones, emociones, entre otros conceptos, generó la motivación de analizarse físicamente.

Este acercamiento al cuerpo se desarrolló mediante bocetos a partir de figuras geométricas y comparaciones con animales para llegar al antropomorfismo, y por medio del desarrollo de personajes imaginarios que contenían emociones. Es así como los estudiantes, a partir de un análisis de movimientos o acciones, empezaron a desglosar y reconocer características físicas de personajes para sus propias composiciones.

También se realizó la creación de mascotas para explorar lo aprendido de gestos y acciones dentro de un animal, que al igual que los demás personajes creados debían tener un fondo, una acción o un gesto que identificara las características más reveladoras del mismo. Los primeros pasos para desarrollar lo mencionado anteriormente se realizaron mediante ejercicios de figuras geométricas para conformar cuerpos.

Para la creación de personajes, los estudiantes debían conocer su contexto, de esta forma comenzaron a analizar culturas sociales a partir de sus propios gustos, las de sus compañeros y la del docente; se intercambió este conocimiento y se reconocieron detalles propios de cada uno.

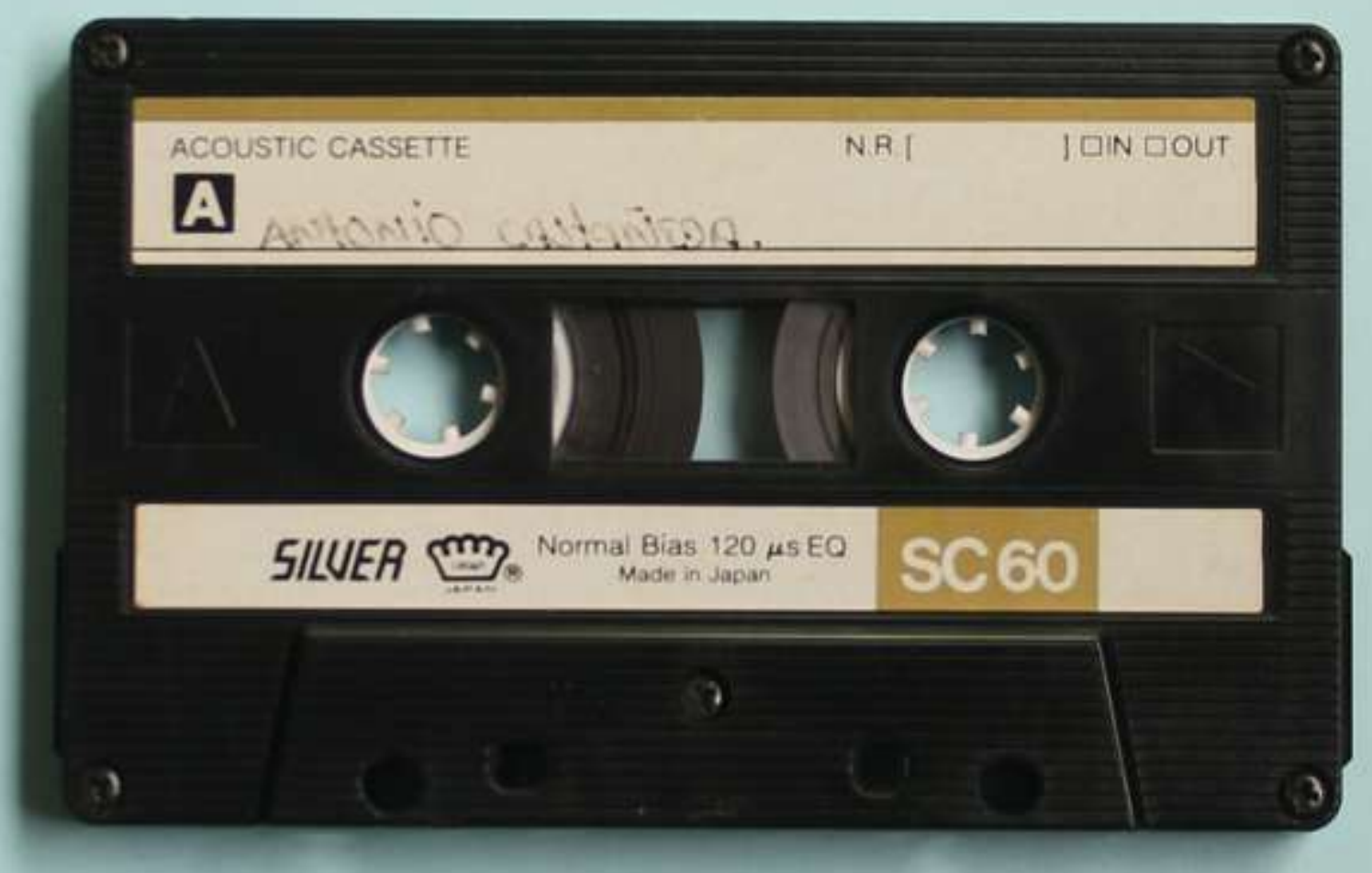

6 Creador de la animación de dibujos animados y productoras de cine como Disne

8 Caricaturista creador de la serie televisiva the Puppet show $y$ Spititing Image.

Para entender mejor el contexto del personaje, se colocó como ejemplo la utilización de vestimenta de una época; un sujeto contemporáneo podría tener una botella de bebida energizante y un celular, acciones del cotidiano que no serían comunes en el Renacimiento.

Hay que destacar que los estudiantes pasaron por múltiples técnicas para conocer la caricatura y asimismo se realizó un recorrido histórico de artistas como Walt Disney, ${ }^{6}$ Peter Nigel, 7 Roger Law, Albert Uderzo, entre otros. Estos también fueron utilizados como referentes en el desarrollo de perfiles y diferencias, la construcción de historias o de momentos divertidos sobre alguien de acuerdo a un estudio previo. Igualmente, se aplicaron teorías prácticas como la composición el manejo de la luz para generar volumen, la disposición de posturas para mejorar el resultado final, la relación de personajes con hecho históricos, el entendimiento de culturas y pensamientos de acuerdo a regiones o estratos sociales $y$ las diversas aplicaciones de las artes visuales en la vida diaria.

Dentro del proceso, los estudiantes reconocieron su cultura visual convencional y se introdujo asimismo el conocimiento de elaboración de películas y videos, las cuales cuentan con un equipo (director, guionista, realizador, psicólogo, artistas visuales, diseñadores, publicistas, libretistas, etc.); esto permitió la realización colectiva del producto artístico a partir de procesos como el Story Board.

De igual forma, se hizo la diferencia conceptual entre tira cómica e historieta, se reconocieron los dibujos animados como referentes para el aprendizaje teniendo en cuenta los gustos personales como por ejemplo Shrek, Los Simpson y Bajo Terra, de los cuales se analizaron formas, características y contextos; además, se realizó un recorrido dentro de la historia del arte con representantes de cada época, lo que permitió contrastar el aprendizaje teórico con la práctica y relacionar esto con los cambios del mundo y la cultura visual actual. Esta última da cuenta de una estética de lo cómico que se relaciona con su contexto, que varía de acuerdo a épocas y acontecimientos sociales; no es lo mismo el personaje de pinocho creado a partir de una experiencia de contextos de la niñez de Disney a la composición de un personaje como el cantante Maluma correspondiente a la época contemporánea: ambas creaciones dan cuenta del medio que está viviendo el autor en ese momento. 


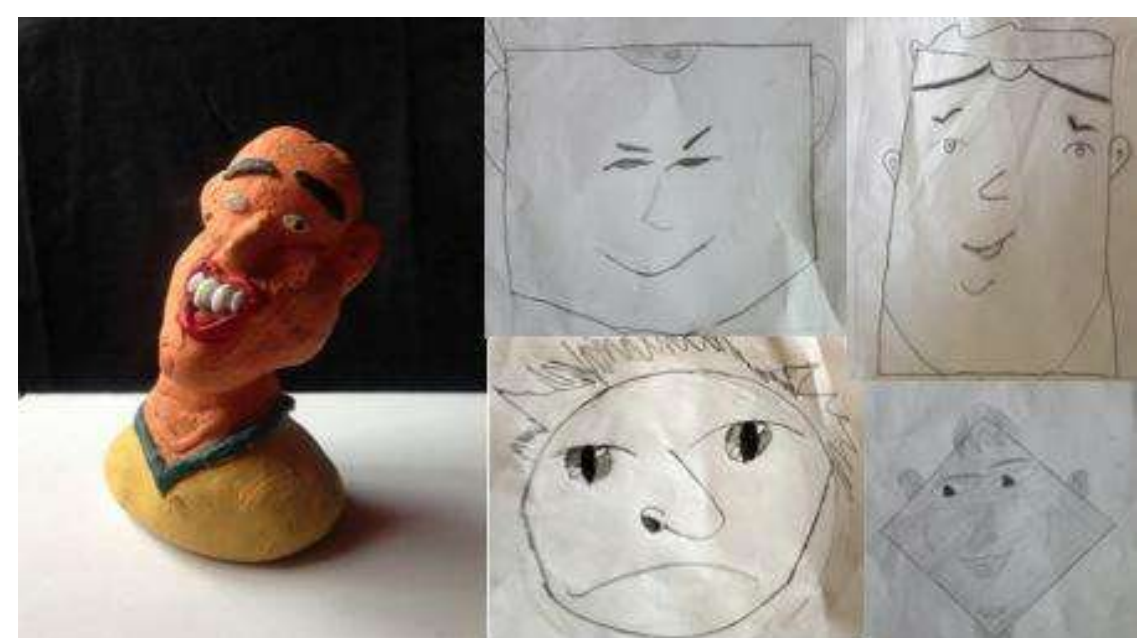

Figura 7. Sin titulo. Obras realizadas por estudiantes parte del proyecto Bogotá en Caricatura A la derecha se evidencia el proceso de aprendizaje de diversos tipos de rostros como el cuadrado redondo, rectangular o diamante, además de los diferentes gestos y facciones del rostro. A la izquierda se evidencia el proceso de aprendizaje de las teorías de caricatura fisionómica con la aplicación del reconocimientos de las formas (cráneo y volúmenes del rostro, entre otras). Fuente: Bogotá en Caricatura.

\section{Conclusiones de investigación}

En el proceso educativo con el grupo Milán se desarrollaron habilidades para el desarrollo de la caricatura y se enseñó la educación artística visual en relación con los contextos culturales. Esto permitió la construcción de pensamientos, valores y convicciones a través de ídolos propios, los cuales influencian los valores básicos del desarrollo social.

Se logró por tanto una convivencia armoniosa dentro de las relaciones sociales que invitan al diálogo y a pensar en el otro, siendo lo interior un claro ejemplo de la asignación de líderes positivos en clase que buscaban el bienestar del grupo para así proceder a las diferentes actividades propuestas en las que la caricatura era la herramienta principal. Lo anterior demuestra su proceso pedagógico y, por ende, su importancia en la educación.

Además, se identificaron procesos de pensamiento desarrollado con los estudiantes en el proyecto Bogotá en Caricatura a partir de la estética de lo cómico, lo cual incentivó al mismo tiempo la creación de una estética propia.

Los estudiantes experimentaron las técnicas artísticas más utilizadas, aprendieron los nuevos roles del artista visual, siendo ellos protagonistas y desarrolladores de un producto con su creatividad, imaginarios, ideas, creencias y gustos propios, entendiendo el valor de la educación artística en todos sus procesos.

Se reconoció el rol del estudiante como artista, lo cual cambia la percepción de su propia identidad, permitiéndole su desarrollo emocional y personal hasta alcanzar una cultura visual avanzada.
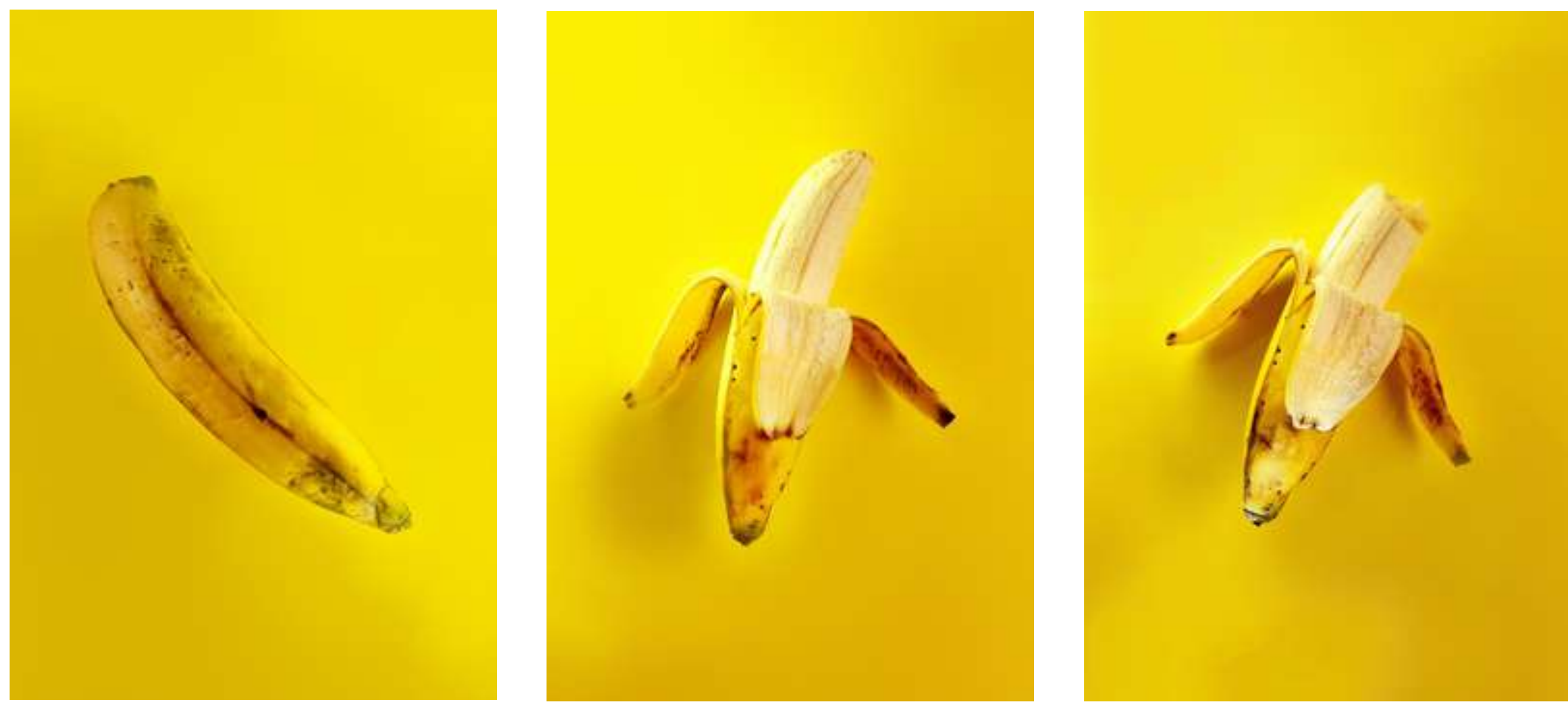

Además de hacer un recorrido histórico, se desarrolló un pensamiento crítico y nuevas formas de entender el mundo, se comprendieron fenómenos culturales ensu contexto y se progresó en las diferentes formas de observar $\mathrm{y}$ conocer las artes visuales.

Los estudiantes comprendieron asimismo la importancia del trabajo en equipo, las condiciones sociales actuales y la importancia de los valores y las posturas críticas par participar activamente en una sociedad democrática. Este proceso educativo de la caricatura permitió del mismo modo generar nuevos conocimientos culturales y la construcción de composiciones a partir de vivencias que determinaro nuevas formas de verse a sí mismo y a los demás. En este sentido, los participantes en el proceso pudieron romper miedos y culpas frente a su cuerpo y su carácter.

Los estudiantes relacionaron la estética de lo cómico con la caricatura morfológica a partir de las proporciones, los tipos de cuerpo de acuerdo a la edad y género. el cuello, los tipos de cráneo, etc.; asimismo, se estudio este tema desde la fisonomía ${ }^{10}$ como, por ejemplo, el análisis

9 Estudio de la forma y su evolución.

10 Estudio de las facciones del rostro. de los ojos, las cejas, las narices, los gestos, las actitudes, además del carácter, las situaciones y los contextos. Lo anterior hace parte de la cultura visual de los estu quienes mediante su quehacer artístico pudieron apropiars de lo cómico y desarrollar su estética propia.

Uno de los logros que se evidenció en el espacio taller fue la importancia de trabajar en grupos para lograr una mejor composición artística y una construcción más armo niosos de la sociedad. Es importante como estudiante reconocer la importancia de ser un sujeto activo dentro de la sociedad y las posibilidades ilimitadas de crear dentro de sus inclinaciones culturales y las compartidas con el docente.

Finalmente, el espacio visto como taller, fuera del contexto institucional, permitió dinámicas diferentes de la educación, en procesos de exploración artística más profunda que en bescuela, donde sin duda es condicionada por contextos formales como la organización, los docente, los padres de familia, los amigos, los compañero de escuela, los medios de comunicación, entre otros; este espacio permitió la construcción de una mirada propia de arte y de la caricatura. 
Referencias

Acaso, M. (2009). Manualidades Expresivas: propuestas para antes del derrumbe. España: Editorial Catarata.

Aguirre, I. (2006). Modelos Formativos en Educación Artistica. Universidad Pública de Navarra.

Alfredo Sarmiento, L. P. (2001). Situación de la Educación Básica, Media y Superior en

Colombia. Bogotá, Colombia: Casa Editorial El Tiempo, Fundación Corona, Fundación Antonio Restrepo Barco.

Antonio, J. (1986). El Dibujo de Humor. Barcelona, España: Ediciones CEAC, S. A.

Barboza, S. (2013). Las Recetas de Sascha Fitness. Venezuela: Ed. Planeta

Barrios, J. L. (2010). El Cuerpo disuelto. Lo colosal y lo monstruoso. México, D. F.: Universidad Iberoamericana Ciudad de México.

Baudelaire, C. (1989). Lo Cómico y La Caricatura. Madrid: Visor ed.

Bergson, H. (1927). La Risa. (A. A. Raggio, Trad.) París: Ediciones Orbis, S.A

Centro de Interés de Artes Plásticas y Visuales de la Secretaría de Educación de Bogotá. (2014). Currículo para la excelencia académica y la formación integral, Orientaciones para el área de Educación Artística. Recuperado de: https://www.educacionbogota.edu.co/archivos/

NOTICIAS/2014/EDUCACION_ARTISTICA.pd

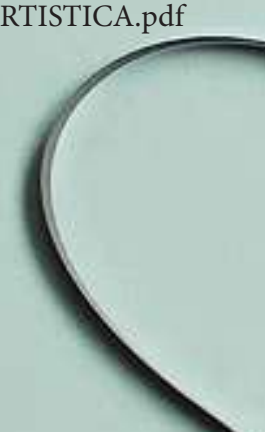

astro, D. G. (2015). Freud y el Humor. Cuenca, U. verdad 68- Psicolod France, W. D. (Escritor). (2012). Erase una vez Walt Disney [Película]. Francia.

Génesis, H. P. (Escritor) y Touch, A. I. (Dirección). (1986). Land of Confusion [Película]. Virginia, USA.

González, B. (Escritor) y República, B. d. (Dirección). (2012). La

Caricatura en Colombia a partir de la Independencia [Película]. Colombia.

Hernández, F. (2007). Espigadores de la Cultura Visual. Barcelona, Espana Octaedro.

Ortiz, M. (2002). Carcajadas que Curan. Agenda Salud, 27(27), 1-8. Rodríguez, R. (1992). Sobre el Objeto de Estudio de la Estética. Ciudad de la Habana, Cuba: Pueblo y Educación.

Romero, P., Rodríguez, G. y Ramírez, J. (2003). Pensamiento Hábil y Creativo. Herramientas pedagógicas para desarrollar procesos de pensamiento. Bogotá: Redipace.

Rouges, J. d. (1959). Tú Carácter. Madrid: M. T. Daimon.

Uribe, C. A. (Escritor). (1995). Incentivos a Escuelas y Maestros [Película].

Walt Disney, S. D. (Escritor) y Disney, S. D. (Dirección). (2003). Destino

Película].

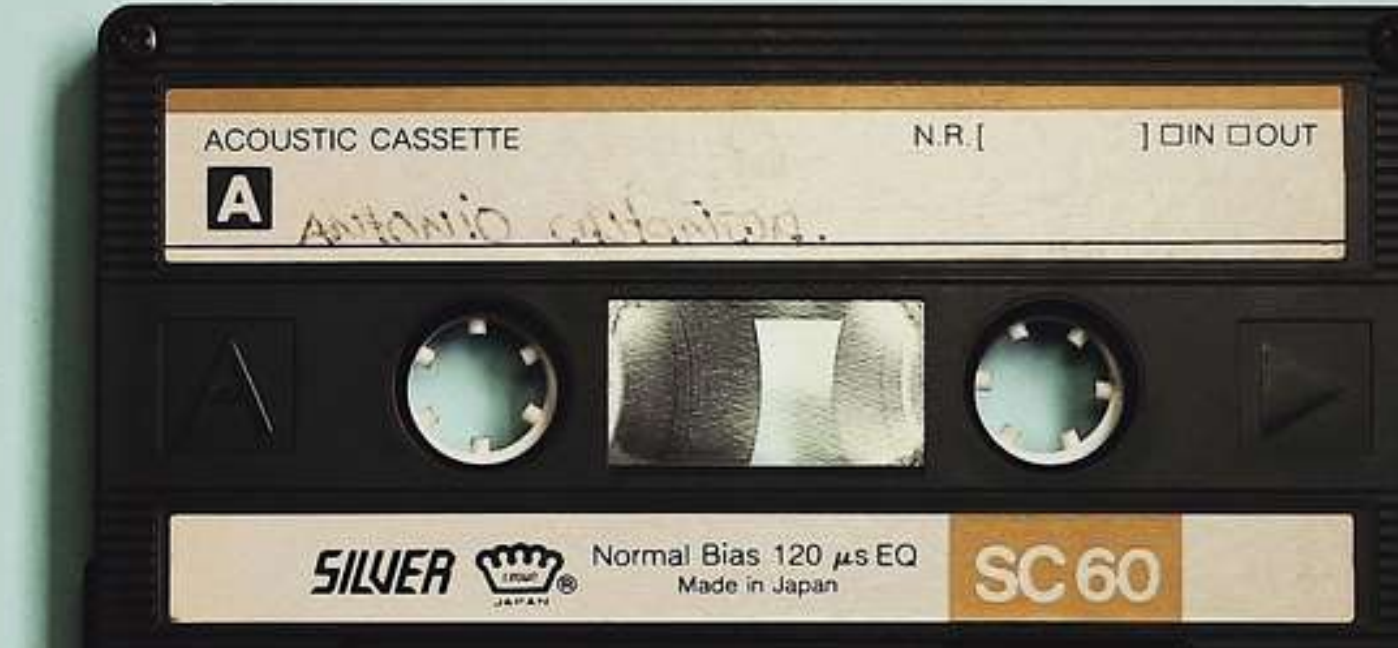

\section{Lina Gabriela Bayona Pineda}

ORCID: 0000-0001-7736-9242

Actualmente cursa la maestría en Divulgación Cientifica y Cultural del Instituto de Estudios de Lenguaje de la unICAMP Campinas-SP. Graduad en la Facultad de Bellas Artes de la Universidad Pedagógica Nacional (Bogotá, Colombia) como licenciada en Artes Visuales, también posee un curso tecnológico profesional en Administración de Obras Arquitectónicas por la Escuela de Artes y Letras Institución Universitaria. En el área de educación tiene participación en creación de metodologías pedagógicas en organizaciones culturales como Fundación Jóvenes con Talento y experiencia como docente de arte en colegios distritales de Bogotá. Ha participado en diversas intervenciones artísticas y exposiciones en espacios culturales y comerciales, también ha desarrollado caricaturas, álbumes, mascotas, historietas e ilustraciones para entidades públicas y privadas. En el área de comunicaciones ha sido periodista, locutora y reportera para varias revistas. Correo electrónico: linagbayona@gmail.com

Artículo de investigación recibido en junio de 2018 y aceptado en agosto de 2018 